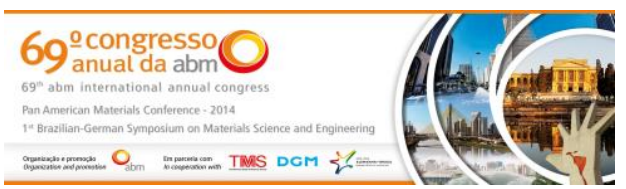

Tema: Soldagem

\title{
MAPEAMENTO DE INCLUSÕES NÃO METÁLICAS DO TIPO SULFETOS DE MANGANÊS (MnS) NO PROCESSO DE SOLDAGEM POR FRICÇÃO COM PINO CONSUMÍVEL EM AÇO C-Mn*
}

\author{
Douglas Martinazzi \\ Mariane Chludzinski \\ Cleber de Lima Lessa ${ }^{3}$ \\ Afonso Reguly 4 \\ Marcelo Torres Piza Paes ${ }^{5}$ \\ Josemar Jantsch Andriotti ${ }^{1}$ \\ Emília Lucena de Oliveira ${ }^{1}$ \\ Marcio Medeiros de Magahães ${ }^{1}$
}

Resumo

O processo de soldagem por fricção com pino consumível (Friction Hydro-Pillar ProcessingFHPP) um método de reparo no estado sólido que consiste no processamento termomecânico de um pino metálico em alta rotação e inserido em um orifício criado no material a reparar. $\mathrm{O}$ pino é pressionado com uma força axial e o aquecimento resultante do atrito dos materiais é suficiente para garantir a plastificação dos mesmos promovendo o preenchimento do orifício e a união dos componentes. Este trabalho é centrado na análise da distribuição de inclusões não metálicas do tipo Sulfetos de Manganês (MnS) presentes em juntas soldadas produzidas por esta técnica com a aplicação de diferentes forças axiais. Micrografias da zona termomecanicamente afetada (ZTMA) foram realizadas por microscopia ótica em amostras polidas e sem ataque para registrar as inclusões. Essas micrografias foram avaliadas via análise de imagens visando a determinação de quantidade, tamanho e área ocupada pelas inclusões nas juntas em juntas soldadas. O mapeamento identificou a distribuição e o tamanho médio das inclusões em função das forças axiais. Concluiu-se que a região analisada é potencialmente crítica no que diz respeito a tenacidade à fratura, uma vez que foi observada uma quantidade considerável de inclusões fragmentadas de dimensões reduzidas.

Palavras-chave: Soldagem por fricção com pino consumível; Análise de Imagens; Inclusões de MnS; ZTMA.

\section{MAPPING OF NON-METALLIC INCLUSIONS OF MANGANESE SULFIDE TYPE (MnS) IN CASE OF FRICTION HYDRO-PILLAR PROCESSING STEEL C-Mn}

\begin{abstract}
The Friction Hydro-Pillar Processing (FHPP) is a solid state repair method that consists in the thermomechanical processing of metallic pin, at high rotational speed, into a hole machined in the material to repair. The rotating pin is pressed with an axial force and the friction heating generated between the two materials is sufficient to ensure the plastification, promoting the fill of the hole and the welding of the components. This work is focused on the analysis of the distribution of nonmetallic inclusions of MnS type (manganese sulfide) present in the welded joints produced by this technique varying the applied axial force. Micrographs of thermomechanical affected zone (TMAZ) were performed by optical microscopy on polished and non-etched samples to characterize the inclusions. These micrographs were evaluated via image analysis in order to determine the amount, size and area occupied by the inclusions in the joints. The mapping identified the distribution and average size of inclusions depending on the axial forces. It was concluded that the considered region is potentially critical in terms of fractures toughness, since it was observed a considerable amount of fragmented inclusions of reduced dimensions.

Keywords: Friction Hydro-Pillar Processing; Image Analysis; Inclusions MnS; TMAZ.

Engenheiro Metalúrgico, Departamento de Metalurgia, Laboratório de Metalurgia Física, Universidade Federal do Rio Grande do Sul (UFRGS), Porto Alegre, RS, Brasil.

2 Engenheiro Metalúrgico, Dr., Depto. de Metalurgia, Laboratório de Metalurgia Física, UFRGS, Porto Alegre, RS, Brasil.

3 Engenheiro Metalúrgico, PROMET, LabFun, IFRS, Caxias do Sul, RS, Brasil.

4 Engenheiro Metalúrgico, Prof. Dr. Depto. Metalurgia, Laboratório de Metalurgia Física, UFRGS, Porto Alegre, RS, Brasil.

5 Engenheiro, D.Sc., Petrobras, Cenpes, Rio de Janeiro, RJ, Brasil.
\end{abstract}

* Contribuição técnica ao 69 Congresso Anual da ABM - Internacional e ao $14^{\circ}$ ENEMET - Encontro Nacional de Estudantes de Engenharia Metalúrgica, de Materiais e de Minas, 21 a 25 de julho de 2014, São Paulo, SP, Brasil. 


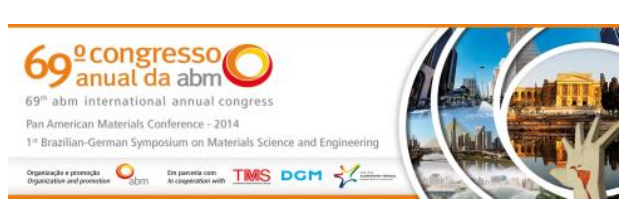

\section{INTRODUÇÃO}

A soldagem por fricção faz parte, segundo a American Welding Society (AWS), de um dos processos de soldagem no estado sólido [1]. O processo é conhecido pelo menos desde 1889, quando foi requerida uma patente nos EUA [2]. Sendo que na Alemanha, durante a $2^{\underline{a}}$ Grande Guerra Mundial, tubos de material termoplástico foram assim unidos. Entretanto, somente com a publicação das experiências realizadas na extinta URSS em 1957, renasceu o interesse sobre o processo [3].

Este processo utiliza a transformação de energia mecânica em calor, gerado através do atrito ("fricção") entre as superfícies que serão unidas. A soldagem ocorre em alta temperatura, na fase sólida, sendo obtida pelo contato em elevada pressão e escoamento plástico entre os materiais envolvidos [4]. A resistência da união se dá em função das propriedades dos materiais empregados, do grau de deformação plástica na interface durante o aquecimento, bem como dos parâmetros do processo [5].

O processo de soldagem por fricção com pino consumível tem algumas características básicas observadas após a união das superfícies, as quais são: ausência de uma região fundida, zona termicamente afetada (ZTA), formação de uma zona termo-mecanicamente afetada (ZTMA) e a formação característica de material deformado plasticamente na forma de anel ao redor da união.

\subsection{Processo}

A soldagem por fricção com pino consumível é uma técnica de reparo que envolve a rotação em velocidades elevadas de um pino metálico consumível que é movimentado em direção a um furo essencialmente circular e previamente usinado na superfície metálica a ser reparada. Sob uma força axial aplicada são geradas sucessões de camadas plastificadas localizadas. As camadas plastificadas aderemse e comprimem uma série de interfaces de cisalhamento Durante o processamento, o consumível é plastificado através do diâmetro do furo e ao longo da espessura da peça. O material plastificado na interface rotacional é mantido numa condição suficientemente viscosa para transmitir forças hidrostáticas, ambas axiais e radiais, para o interior do furo, permitindo a união metalúrgica [6]. Ao final do processo o movimento de rotação é cessado e uma pressão de igual ou de maior valor é aplicada, para a etapa de forjamento. A sequência do processo é apresentada na Figura 1.

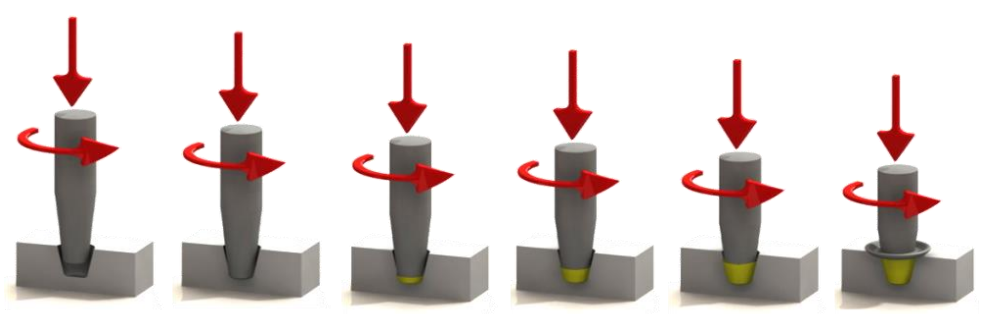

Figura 1: Desenho esquemático do processo.

Os parâmetros utilizados para controlar o processo de soldagem são a velocidade de rotação, força axial e comprimento/taxa de queima [7] que representa a quantidade de material plastificado que preenche o furo, podendo ser medido pelo deslocamento vertical ou pela diminuição do comprimento do pino.

\footnotetext{
* Contribuição técnica ao $69^{\circ}$ Congresso Anual da ABM - Internacional e ao 14ํㅡㄹ ENEMET - Encontro Nacional de Estudantes de Engenharia Metalúrgica, de Materiais e de Minas, 21 a 25 de julho de 2014, São Paulo, SP, Brasil.
} 


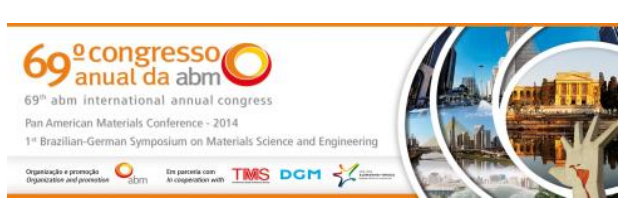

Para o estudo do comportamento mecânico de um aço também é importante avaliar a ocorrência de deformação das fases presentes. A plasticidade relativa da fase MnS em relação à matriz apresenta uma grande influência no comportamento do mesmo. O índice de plasticidade tem valores que variam de zero, para as inclusões que não deformam em relação à matriz, até 1, para inclusões que deformam com a mesma relação que a matriz. No caso de ser igual a 1, as ligações químicas na interface inclusão-aço se quebram e as inclusões formam elipses sem a ocorrência de descontinuidades no aço. Não obstante, mudanças na solubilidade do MnS ou variações na composição ou tratamento térmico do aço, influenciam a deformação relativa da fase e da matriz em torno da fase. A taxa de deformação também afeta a deformabilidade das inclusões de sulfeto de manganês. Para valores baixos de taxa de deformação, as inclusões deformam-se de maneira similar à matriz e essa deformabilidade relativa se reduz ao aumentar a taxa de deformação, o que pode causar o surgimento de trincas na matriz [15].

As inclusões não metálicas, no caso de estudo os sulfetos de manganês, podem ser quantificadas por diferentes métodos: análise automática de imagens baseada em microscopia ótica, inspeção por ultrassom, magnetismo, raios-X entre outros métodos. Os dados gerados por essas técnicas são tratados por métodos estatísticos [14], porém neste trabalho são considerados todos os valores medidos, desde o mínimo até o máximo, e não na probabilidade de encontrar valores dentro de uma faixa para certo grau de confiança aços.

\section{MATERIAIS E MÉTODOS}

As juntas soldadas foram realizadas no centro de pesquisas TWI em Cambridge Inglaterra. Para o processamento das amostras foi utilizada uma máquina modificada de soldagem por atrito NEI - John Thompson modelo FW-13 com uma potência máxima de $43 \mathrm{~kW}$ e uma força axial limite de $480 \mathrm{kN}$. Todas as amostras foram fabricadas utilizando uma velocidade rotacional de $1550 \mathrm{rpm}$. Os ensaios foram realizados em diferentes forças axiais, variando a magnitude: $50 \mathrm{kN}, 200 \mathrm{kN}$ e $400 \mathrm{kN}$. A Figura 2 apresenta o desenho esquemático do pino e da chapa com furo usinado do metal base.

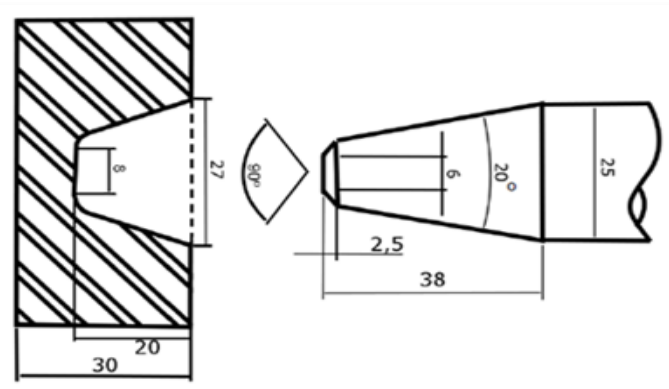

Figura 2: Desenho esquemático do pino consumível e da cavidade do metal base.

Originalmente classificado como EN14, obtidos a partir de barras cilíndricas laminadas a quente. As composições químicas foram obtidas no espectrômetro de marca SPECTRO, modelo Spectrolab e estão expressos na Tabela 1. Na Tabela 2 estão listados os parâmetros de soldagem utilizados.

\footnotetext{
* Contribuição técnica ao $69^{\circ}$ Congresso Anual da ABM - Internacional e ao 14ํㅡㄹ ENEMET - Encontro Nacional de Estudantes de Engenharia Metalúrgica, de Materiais e de Minas, 21 a 25 de julho de 2014, São Paulo, SP, Brasil.
} 


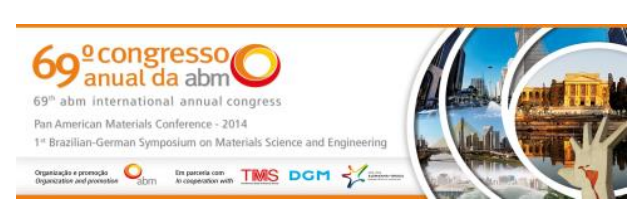

termicamente afetada e zona termo-mecanicamente afetada. Além dessas, tem o material base do pino e o material do componente a ser reparado.

Para análise microestrutural as amostras foram cortadas de modo que fosse seccionado o meio da solda, conforme representado na Figura 4, e novamente cortada ao meio pela simetria radial da mesma. As análises metalográficas serviram para a identificação das microestruturas das regiões desde o metal base através da região processada até o pino, utilizando microscopia ótica e eletrônica. Os equipamentos utilizados foram microscópio ótico (MO) da marca OLYMPUS (modelo BX51M, com câmera acoplada com reflexão de luz branca). As amostras foram lixadas e polidas, após isto foram atacadas quimicamente com solução de Nital $2 \%$, com o objetivo de revelar as regiões e microestruturas da junta soldada.

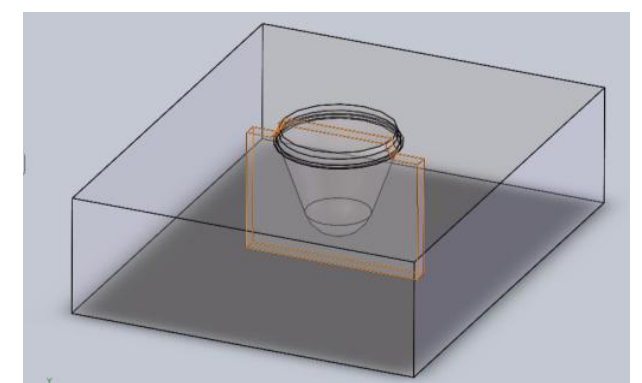

Figura 4: Posição da secção das amostras.

A zona de ligação (ZL) nada mais é do que o local onde ocorre a adesão entre as peças. Observando esta zona em uma análise metalográfica, fica visível apenas uma linha ao longo da geometria do furo.

A ZTA é a zona onde a microestrutura e as propriedades mecânicas apenas sofrem a influência do calor gerado durante o processo de soldagem. Fazendo analogia com processos onde ocorre fusão dos materiais, a microestrutura desta zona é resultante das transformações estruturais do metal base associadas com os ciclos térmicos e deformações durante a soldagem.

A ZTMA difere da ZTA por sofrer maior aquecimento e também por sofrer deformação do processo de fricção, resultando em uma microestrutura heterogênea com grãos deformados.

A Figura 5 apresenta as diferentes regiões afetadas identificadas como ZTAcHAPA, ZTMAchapA, ZTMApINo e ZTApINo [18] e o material base do pino e da chapa.

\footnotetext{
* Contribuição técnica ao $69^{\circ}$ Congresso Anual da ABM - Internacional e ao 14ํㅡㄹ ENEMET - Encontro Nacional de Estudantes de Engenharia Metalúrgica, de Materiais e de Minas, 21 a 25 de julho de 2014, São Paulo, SP, Brasil.
} 

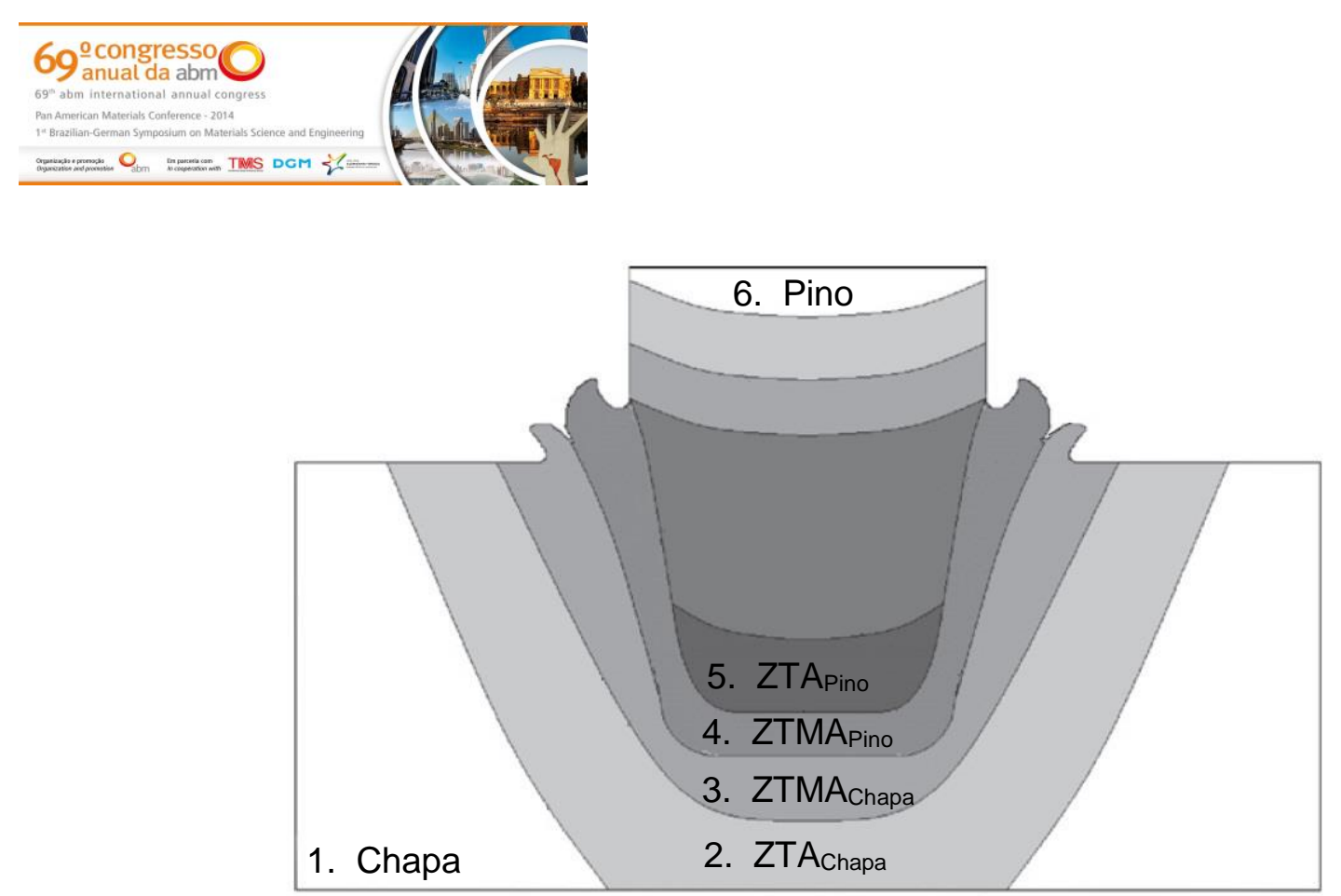

Figura 5: llustração das áreas observadas em uma junta soldada pelo processo FHPP [18].

A região de interesse para o estudo é a região da ZTMA. As inclusões na ZTA, por não sofrerem deformações devido o processo de ficção mecânica, conforme apresentado na Figura 6, não foram submetidas a análises neste trabalho.

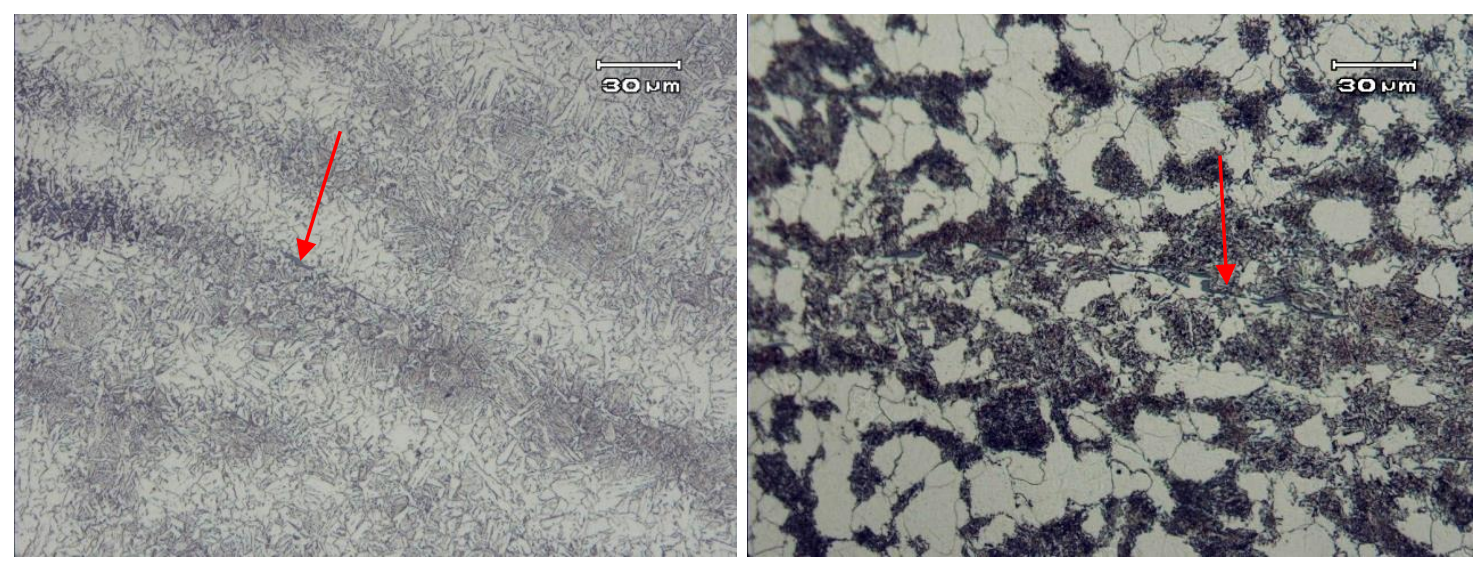

Figura 6: Inclusões não processadas na ZTA.

\subsection{Metodologia da Análise de Inclusões}

Após as regiões com variações microestruturais entre a ZTA e a ZTMA estarem marcadas nas amostras, estas foram polidas novamente seguindo mesmo procedimento já descrito. Na superfície do plano seccionado polido e sem ataque químico foram realizadas micrografias da superfície, aumento de 500 vezes, para as análises das inclusões presentes no pino e na chapa. As micrografias foram organizadas em áreas conforme sua posição na amostra para poderem ser realizadas as análises dos teores de inclusão conforme a posição na amostra. Também foram realizadas marcações de a cada $1 \mathrm{~mm}$ no sentido lateral nas amostras de 50 e $200 \mathrm{kN}$ e a cada $0,5 \mathrm{~mm}$ na amostra de $400 \mathrm{kN}$.

Com o auxílio do software de análise de imagens Image J (v1.46r 32 bits) [14], todas as micrografias sofreram ajustes de iluminação, correções de brilho e contraste e, a então binarizadas. Puderam-se analisar várias micrografias em um "stack" (pilha de imagens) com o ajuste da escala e seleção das inclusões conforme a tonalidade em bit. O resultado gerado pelo software foi coletado em planilhas de Excel.

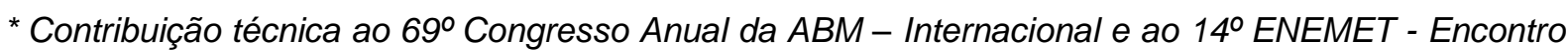
Nacional de Estudantes de Engenharia Metalúrgica, de Materiais e de Minas, 21 a 25 de julho de 2014, São Paulo, SP, Brasil. 
Conforme apresentado na Figura 7, a sequência de imagens, partindo da micrografia até o resultado final gerado, após todos os tratamentos realizados com o software. $O$ resultado gerado pelo software foi: número de inclusões por imagem, porcentagem em área ocupada pelas inclusões, tamanho médio em área das inclusões por imagem e a área total ocupada pelas inclusões em cada imagem.

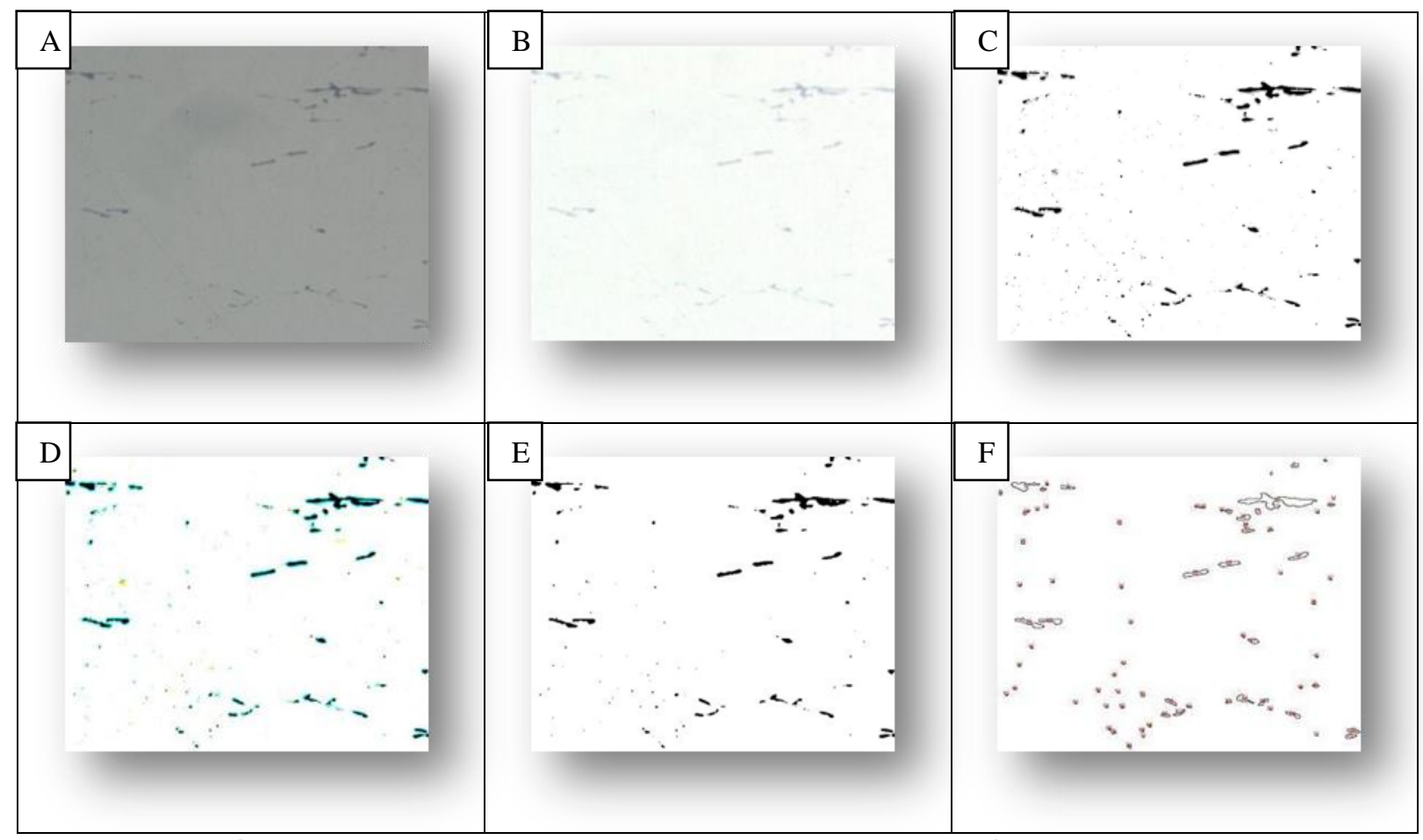

Figura 7: Etapas do tratamento de imagem nas micrografias de inclusão

As análises de distribuição de inclusões e de estatística têm como base a norma ASTM E1245 - 03 [16] e os resultados, para interpretação de tamanhos, foram comparados com a norma ASTM E45 [17]. Os resultados obtidos para cada imagem da análise de inclusões são porcentagem de área ocupada pelas inclusões (Aa), número de inclusões por $\mathrm{mm}^{2}(\mathrm{Na})$ e tamanho médio das inclusões em área (Tmed) como apresentado por Caregnato [15].

A análise em Microscópio Eletrônico de Varredura (MEV) Shimadsu (modelo SSX-550 SUPERSCAN com sistema de análise de imagens) foi realizada para constatar a presença de inclusões de sulfetos de manganês, apresentado na figura 8, no material da Chapa e do Pino. Conforme apresentado na figura 10, as inclusões no material do Pino e da Chapa possuem uma diferença de $90^{\circ}$, ou seja, estão alongadas e orientadas conforme o bandeamento do material.

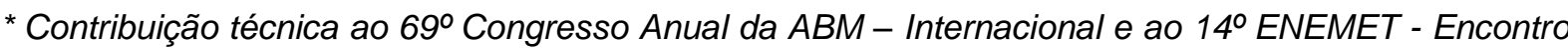
Nacional de Estudantes de Engenharia Metalúrgica, de Materiais e de Minas, 21 a 25 de julho de 2014, São Paulo, SP, Brasil.
} 

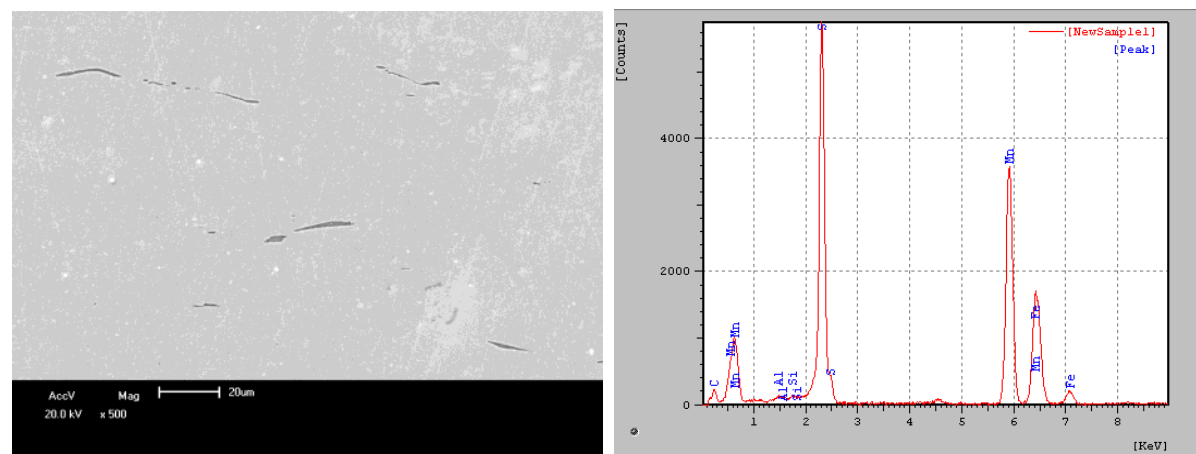

Figura 8: Inclusões no material (à esquerda) e espectro do EDS sobre a inclusão (à direita).

\section{RESULTADOS E DISCUSSÃO}

As amostras foram delimitadas na região da ZTMA e as análises, conforme mencionado, ficaram restritas nesta zona. Na Figura 9 é apresentada a delimitação da ZTMA, onde as linhas escuras representam a marcação da ZTMA e a linha mais clara central é a marcação da ZL. Também foram traçadas linhas a cada $1 \mathrm{~mm}$ nas imagens para facilitar a visualização de como foram feitas as micrografias.

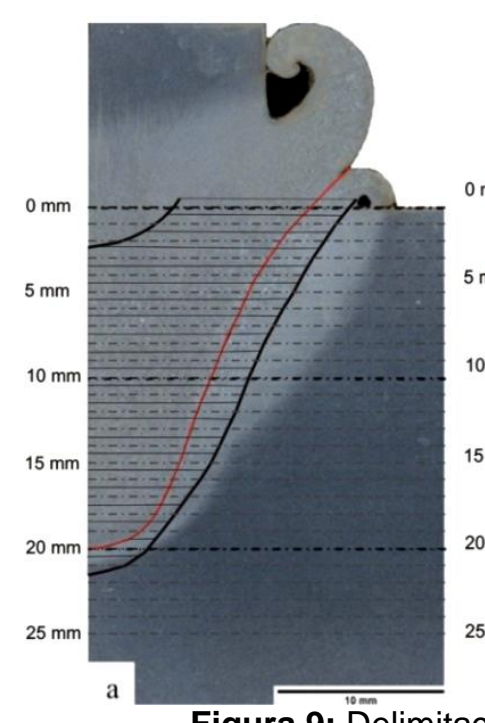

Figura 9: Delimitação da ZTMA 50KN(a), 200KN

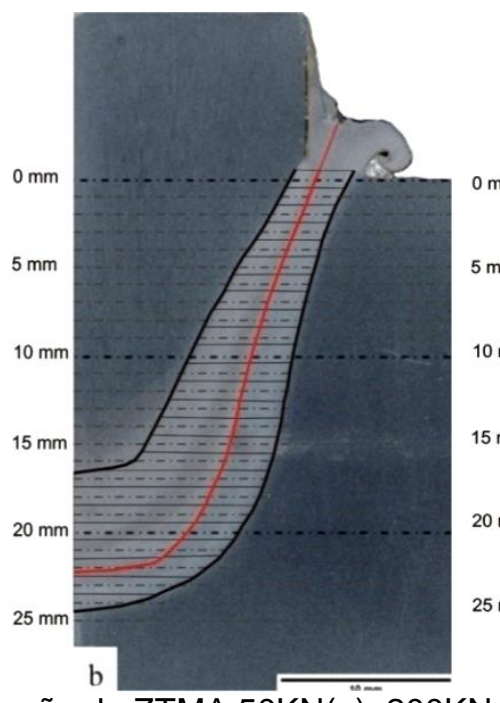

$\mathrm{KN}(\mathrm{b})$

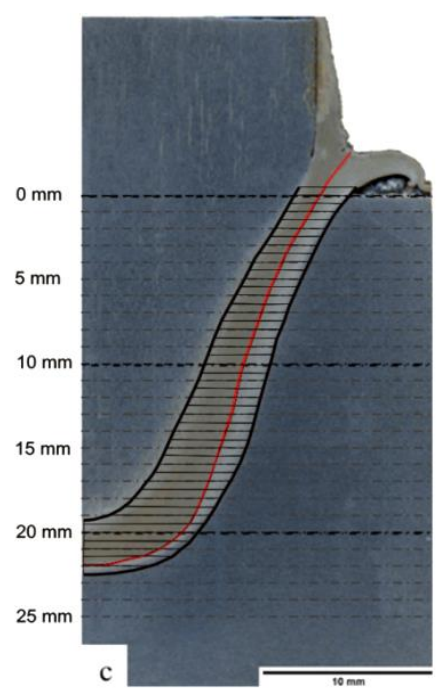

(b) e $400 K N(c)$.

Inicialmente, as análises foram realizadas nas micrografias do metal base e do pino, em regiões sem a influência do calor e nem do processo de fricção. Nas micrografias do pino não foram encontradas grandes diferenças entre quantidade e formato das inclusões, conforme apresentado na figura 10. As inclusões estão alongadas no sentido de laminação.

\footnotetext{
* Contribuição técnica ao 69ำ Congresso Anual da ABM - Internacional e ao 14ํㅡㄹ ENEMET - Encontro Nacional de Estudantes de Engenharia Metalúrgica, de Materiais e de Minas, 21 a 25 de julho de 2014, São Paulo, SP, Brasil.
} 

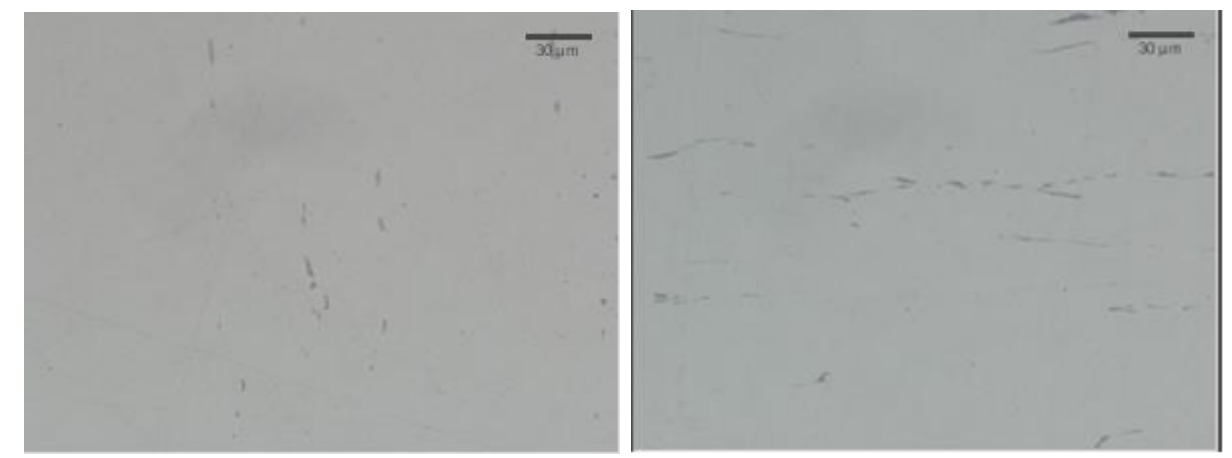

Figura 10: Micrografias representativas do material do pino e da chapa não processado.

Estas micrografias foram realizadas no pior campo de inclusões do pino e da chapa e os resultados das análises no ImageJ destas imagens serviram como base para comparação com os resultados das análises da ZTMA das amostras.

Durante a análise, foi observada que há uma reorientação das inclusões ao longo da ZTMA, essa reorientação tende a seguir de forma progressiva o fluxo de material em direção ao local onde há formação da rebarba. Esse efeito é apresentado de forma esquemática na figura 11, onde foram colocadas as micrografias de uma região com maior quantidade de inclusões para demonstrar tal efeito.

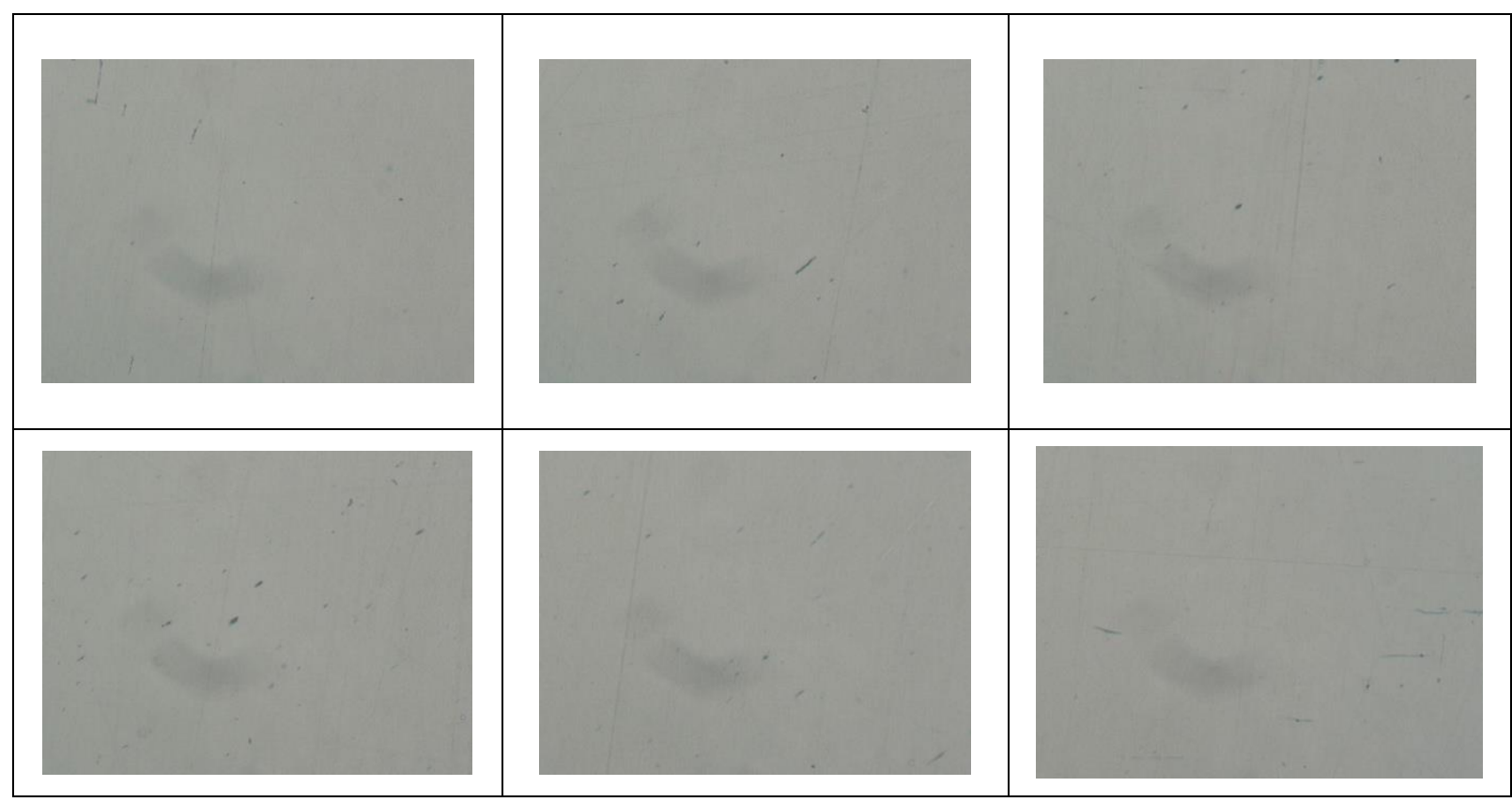

Figura 11: Sequência de micrografias que mostra a reorientação das inclusões ao longo de uma mesma linha horizontal.

É necessário considerar que a análise leva em conta apenas um plano de toda a solda, contudo por possuir geometria radial é admissível extrapolar esses resultados para todos outros planos da solda [15]. No entanto, pela possível variação nos resultados dos outros planos, os gráficos possuem um caráter representativo da distribuição e tamanho das inclusões de MnS na ZTMA da solda. De todas as amostras analisadas, a ZTMA foi dividida em 2 partes: do Pino e da Chapa, sendo a linha de divisão a ZL.

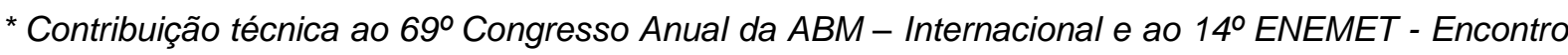
Nacional de Estudantes de Engenharia Metalúrgica, de Materiais e de Minas, 21 a 25 de julho de 2014, São Paulo, SP, Brasil.
} 


\subsection{Força Axial de 50kN}

Os resultados, após o tratamento das 837 imagens da varredura realizada na superfície do corpo de prova da amostra com força axial de $50 \mathrm{kN}$, foram coletados e classificados conforme o tamanho de cada inclusão. Estes resultados de porcentagem de área ocupada pelas inclusões, número de inclusões por $\mathrm{mm}^{2} \mathrm{e}$ tamanho médio das inclusões foram posteriormente sintetizados em curvas de nível através de escalas de cores e sobrepostos à amostra para melhor visualização dos resultados sobre a área da ZTMA. A figura 12 apresenta os resultados de tamanho médio das inclusões $\left(e m \mu m^{2}\right.$ ), área ocupada pelas inclusões (\% em área) e número de inclusões por $\mathrm{mm}^{2}$.

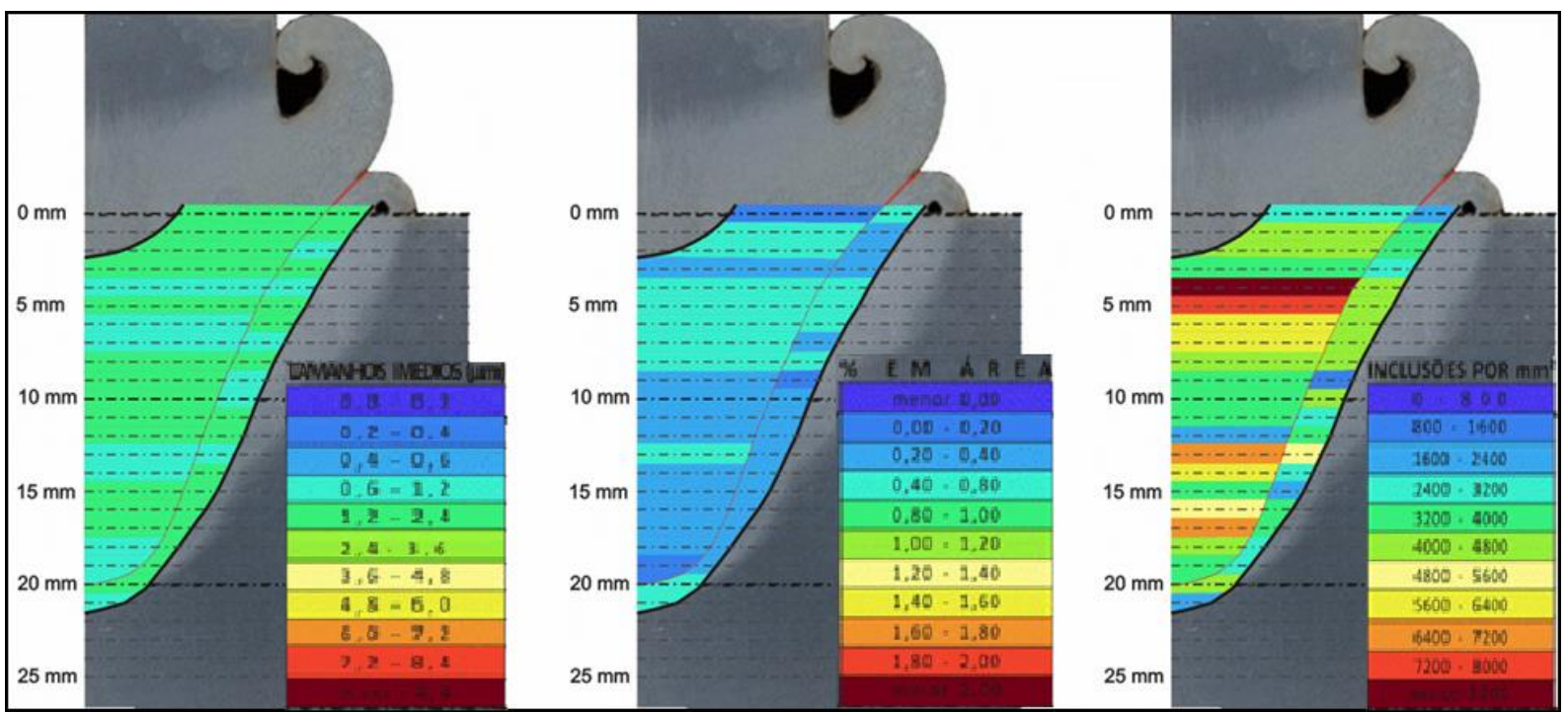

Figura 12: Resultados obtidos para amostra de 50kN: (à esquerda) Tamanho médio das inclusões; (ao centro) Porcentagem de área ocupada pelas inclusões; (à direita) Número de inclusões por mm².

Observando o resultado sobre o tamanho médio das inclusões e a porcentagem em área, ficaram praticamente homogêneos sobre toda a ZTMA, porém a quantidade de inclusões teve alguma alteração, principalmente ao longo da ZTMA do pino.

\subsection{Força Axial de $200 \mathrm{kN}$}

Os resultados, após o tratamento das 670 imagens de inclusões do corpo de prova da amostra com força axial de $200 \mathrm{kN}$, também foram coletados e classificados. A figura 13 apresenta os resultados de tamanho médio das inclusões $\left(e m \mu m^{2}\right)$, área ocupada pelas inclusões (\% em área) e número de inclusões por $\mathrm{mm}^{2}$.

\footnotetext{
* Contribuição técnica ao 69 Congresso Anual da ABM - Internacional e ao 14ํㅡㄹ ENEMET - Encontro Nacional de Estudantes de Engenharia Metalúrgica, de Materiais e de Minas, 21 a 25 de julho de 2014, São Paulo, SP, Brasil.
} 


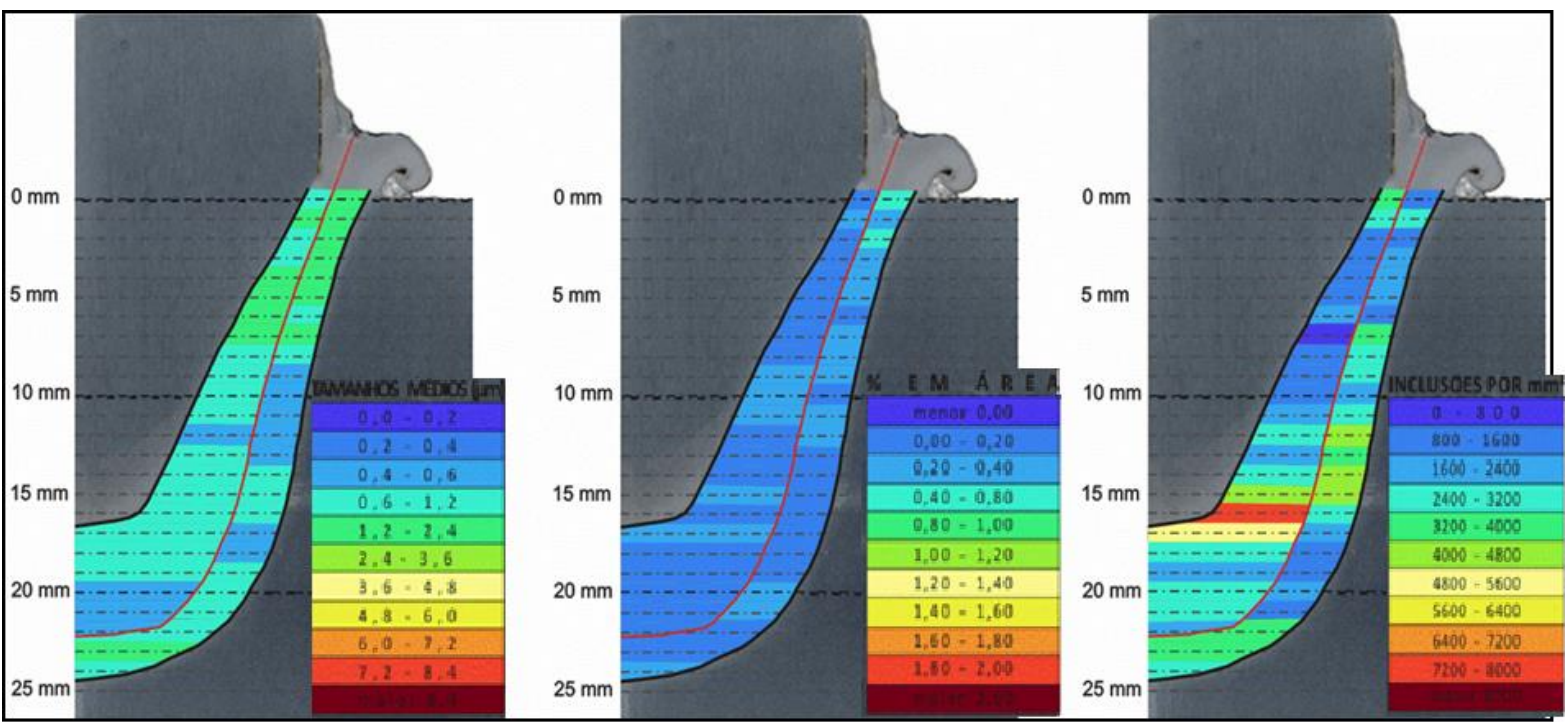

Figura 13: Resultados obtidos para amostra de $200 \mathrm{kN}$ : ((à esquerda) Tamanho médio das inclusões; (ao centro) Porcentagem de área ocupada pelas inclusões; (à direita) Número de inclusões por mm².

Observando o resultado sobre o tamanho médio das inclusões e a porcentagem em área, como foi o caso da amostra de força axial $50 \mathrm{kN}$, ficaram praticamente homogêneos sobre toda a ZTMA do pino e da chapa. A quantidade de inclusões teve um aumento no ponto de $17 \mathrm{~mm}$ na ZTMA do pino e na região entre 10 e $15 \mathrm{~mm}$ da chapa, que é a região central desfavorecendo a qualidade de adesão da solda.

\subsection{Força Axial de $400 \mathrm{kN}$}

O mapeamento sobre o corpo de prova da amostra de Força Axial de $400 \mathrm{kN}$, gerou 598 imagens, todas elas foram tratadas e os resultados foram classificados seguindo a metodologia empregada nos corpos de prova de Força Axial de 50 e $200 \mathrm{kN}$. A figura 14 apresenta os resultados de tamanho médio das inclusões $\left(\mathrm{em} \mu \mathrm{m}^{2}\right)$, área ocupada pelas inclusões (\% em área) e número de inclusões por $\mathrm{mm}^{2}$.

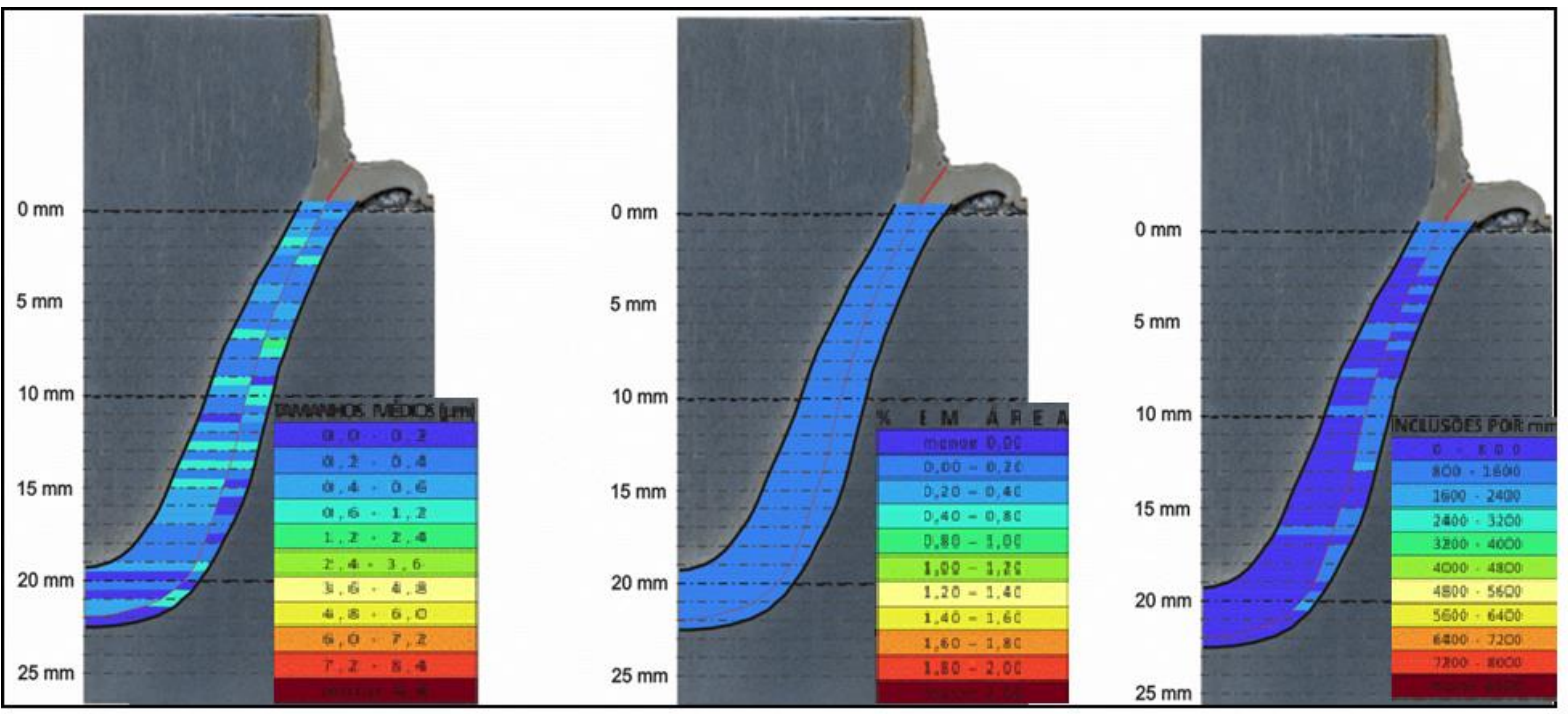

Figura 141: Resultados obtidos para amostra de 400kN: (à esquerda) Tamanho médio das inclusões; (ao centro) Porcentagem de área ocupada pelas inclusões; (à direita) Número de inclusões por mm².

\footnotetext{
* Contribuição técnica ao 69 Congresso Anual da ABM - Internacional e ao 14ํㅡㄹ ENEMET - Encontro Nacional de Estudantes de Engenharia Metalúrgica, de Materiais e de Minas, 21 a 25 de julho de 2014, São Paulo, SP, Brasil.
} 
10 Nicholas ED. Underwater Friction Welding for Electrical Coupling of Sacrificial Anodes. In: 16th Offshore Technology Conference; 1984; Houston, USA. 1984.

11 Blakemore GR. Underwater application of state of the art portable friction stud welding equipment. In: International Workshop on Underwater Welding of Marine Structures; 1994; New Orleans, USA. American Bureau of Shipping; 1994.

12 Kiessling R, Lange N. Non Metallic Inclusions in Steel. 2nd ed. Londres: Metals Society; 1978.

13 Atkinson HV, Shi G. Characterization of inclusions in clean steels: a review including the statistics of extremes methods. Progress in Materials Science. 2003;48:457-520.

14 Wayne Rasbaand, National Instituts of Health, USA. Versão 1.46r 32 bits. [acesso em 2012]. Disponível em: http://rsbweb.nih.gov/ij/.

15 Caregnato MF. Distribuição de sulfetos de manganês no processo de soldagem FHPP em aço C-Mn [dissertação PPGE3M]. Porto Alegre: UFRGS; 2013.

16 American Society for Testing and Materials. E1245 - 03 (08): Standard Practice for Determining the Inclusion or Second-Phase Constituent Content of Metals by Automatic Image Analysis. West Conshohocken; 2008.

17 American Society for Testing and Materials. E45:Standard Test Methods for Determining the Inclusion Content of Steel. West Conshohocken; 2013.

18 Hattingh DG, Bulbring DLH, Els-Botes A, James MN. Processparameter influence on performance of friction taper stud welds in AISI 4140 steel. Materials and Design. 2011;32:3421-30.

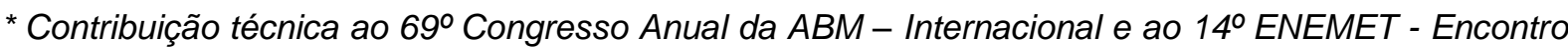
Nacional de Estudantes de Engenharia Metalúrgica, de Materiais e de Minas, 21 a 25 de julho de 2014, São Paulo, SP, Brasil. 